\title{
Trend and effects of high-deductible health insurance plans in the health care system: financial access problems in management of cognitive impairment
}

\author{
Abdulrahman A Alnijadi, PharmD; Minghui Li, PhD; Jun Wu, PhD; Xiaomo Xiong, MS; and Z Kevin Lu, PhD
}

\section{What is already known about this subject}

- Employers are increasingly expanding their use of high-deductible health plans (HDHPs), and more adults in the United States obtained private health insurance from their employers.

- Cognitive impairment leads to lower quality of life, worsened neuropsychiatric problems, and increased disability, as well as an increase in the cost of health care.

- Financial access problems are a common issue among individuals with cognitive impairment because they are more likely to seek medical assistance.

\section{What this study adds}

- This study found an increase in the prevalence of HDHP enrollment from 2010 to 2018 in individuals with cognitive impairment, which was similar to the prevalence of HDHPs in other populations.

- Research found that individuals with cognitive impairment who had health plans with HDHPs experienced more financial access problems than those who had plans without HDHPs.

- This study provides helpful guidance to employers and health care decision makers when choosing the appropriate health plan for individuals with cognitive impairment.

\begin{abstract}
Author affiliations
Abdulrahman A Alnijadi, ${ }^{\star}$ PharmD, Department of Clinical Pharmacy and Outcomes Sciences, University of South Carolina, Columbia, and Department of Pharmacy Practice, College of Clinical Pharmacy, King Faisal University, Al-Ahsa, Saudi Arabia. Minghui Li, ${ }^{\star}$ PhD, Department of Clinical Pharmacy and Translational Science, University of Tennessee Health Science Center, Memphis, and Jun Wu, PhD, Department of Pharmaceutical and Administrative Sciences, Presbyterian College, Clinton, SC. Xiaomo Xiong, MS, and Z Kevin Lu, PhD, Department of Clinical Pharmacy and Outcomes Sciences, University of South Carolina, Columbia.
\end{abstract}

\section{AUTHOR CORRESPONDENCE: \\ Z Kevin Lu, 803.777.2653; \\ lu32@email.sc.edu \\ ${ }^{\star}$ These authors contributed equally to this work.}

\section{ABSTRACT}

BACKGROUND: High-deductible health plans (HDHPs) are characterized by higher deductibles and lower monthly premiums compared with a typical health plan. HDHPs may reduce, or delay, needed care, which will ultimately lead to poorer access to care for chronically affected participants.

OBJECTIVES: To (1) investigate the HDHP enrollment trend and (2) determine the effects of HDHPs on financial access
J Manag Care Spec Pharm. 2022;28(1):7-15

Copyright $\odot 2022$, Academy of Managed Care Pharmacy. All rights reserved.

problems for individuals with self-reported cognitive impairment.

METHODS: Data between 2010 and 2018 were obtained from the National Health Interview Survey (NHIS). Individuals with cognitive impairment were identified if they were 
limited by memory difficulties. Problems regarding financial access to health care were assessed based on 6 survey questions from the Centers for Disease Control and Prevention. Multivariable logistic regressions were implemented to evaluate the effects of HDHPs.

RESULTS: This study identified 1,148 individuals with cognitive impairment, representing 3.9 million individuals in the United States from 2010 to 2018. A nearly 2 -fold increase in HDHP enrollment with cognitive impairment was observed from 2010 (20.9\%) to 2018 (41.9\%). This increase is similar to that reported for noncognitively impaired individuals. After controlling for possible confounding variables, cognitively impaired individuals with $\mathrm{HDPHs}$ were more likely to have overall financial access difficulties compared with those without $\mathrm{HDHPs}(\mathrm{OR}=1.17,95 \% \mathrm{Cl}=0.88-1.56, P=0.271)$, but this likelihood was not statistically significant.

CONCLUSIONS: HDHPs are intended to support effective care options and reduce health care costs. However, our research found that among individuals with cognitive impairment, those with HDHPs experienced some financial access problems, such as affording medical care, follow-up care, and specialists, than those without HDHPs, indicating that HDHPs might have unintended consequences for health care usage.

High-deductible health plans (HDHPs) are characterized by higher deductibles and lower monthly premiums than traditional health plans. ${ }^{1}$ The Internal Revenue Service describes an HDHP as any plan with a deductible of at least $\$ 1,400$ per individual or $\$ 2,800$ per family. ${ }^{2}$ Total annual out-of-pocket expenditures for an HDHP cannot be more than $\$ 6,900$ per individual or $\$ 13,800$ per family. ${ }^{2}$ Recent studies show that employers are rapidly increasing their implementation of HDHPs. ${ }^{3}$ In addition, more than $60 \%$ of adults aged 18-64 years in the United States receive private health insurance through their workplaces. ${ }^{4}$ Individuals typically prefer lower-cost health plan options to cut costs. HDHP advocates use this argument regarding patient choices for health plans. ${ }^{5}$ From the rule of supply and demand, higher prices eventually lead to lower demand rates ${ }^{6}{ }^{6}$ and this also applies when the participants choose their health insurance. Low insurance rates will be in higher demand, attracting more participants looking for health insurance.

One of the benefits of an HDHP is that it has lower premiums than typical health plans. However, individuals may face a substantial cost burden following a medical emergency because of the high insurance deductible. Approximately $40 \%$ of Americans would not be able to afford an emergency expense of $\$ 400$ without borrowing money or selling their belongings. ${ }^{7}$

Participants with HDHPs may experience a decrease or delay in care, resulting in less access to care for chronically affected participants. ${ }^{8}$ The chronic condition assessed in this study was cognitive impairment, which refers to memory difficulties, acquiring new knowledge, concentration, or making decisions that affect their everyday lives. ${ }^{9}$ Cognitive impairment can vary from mild to severe and may be caused by Alzheimer disease and other dementias, strokes, traumatic brain injuries, and developmental disabilities. ${ }^{9}$ Furthermore, the size of the population with cognitive impairment and dementia will expand in the coming years because of the rapid increase in the population of older adults. ${ }^{10}$

Our emphasis in this research was to assess the effects of HDHPs on potential financial access problems for individuals with self- or family-reported cognitive impairment. Since financial judgment is compromised by cognitive impairment, these individuals are in jeopardy of fraud and are vulnerable to financial exploitation by caregivers. ${ }^{11}$ Also, cognitive impairment leads to lower quality of life, worsened neuropsychiatric problems, and increased disability, ${ }^{12,13}$ as well as an increase in the cost of health care. ${ }^{14}$ Furthermore, financial access problems are a common issue among individuals with cognitive impairment because they are more likely to seek medical assistance. ${ }^{15}$

To date, there are no studies that have focused on issues of financial access to health care use by HDHP status among individuals with cognitive impairment because there is a lack of information on cognitive status,$^{16}$ and the majority of the existing studies have used screening tests or clinical tests to assess cognitive impairment. ${ }^{17,18}$ It is very possible that cognitive impairment has been underdiagnosed. ${ }^{19}$ Also, the accuracy of the diagnosis may vary depending on the tools used to detect cognitive impairment. ${ }^{20}$ Furthermore, the trend of financial access to health care use by HDHP status is still unknown among people with cognitive impairment.

The purpose of our study was to (1) investigate the HDHP enrollment trend of individuals with cognitive impairment over time and (2) analyze financial access for individuals with cognitive impairment to health care use.

\section{Methods}

\section{DATA SOURCE AND STUDY POPULATION}

Data between 2010 and 2018 were obtained from the National Health Interview Survey (NHIS), which is conducted by the Centers for Disease Control and Prevention. The NHIS is an annual cross-sectional survey of the US population that is performed on a nationally representative basis. The participants in this survey volunteer for face-toface interviews regarding their health. ${ }^{21}$ The primary goal 


\section{TABLE 1}

Baseline Characteristics of Individuals with Cognitive Impairment by HDHP

\begin{tabular}{|c|c|c|c|c|c|}
\hline & \multicolumn{2}{|c|}{$\begin{array}{l}\text { HDHP group } \\
(n=1,471,474)\end{array}$} & \multicolumn{2}{|c|}{$\begin{array}{l}\text { Non-HDHP group } \\
(n=2,443,952)\end{array}$} & \multirow[b]{2}{*}{$P$ value } \\
\hline & $\mathbf{n}$ & $\begin{array}{c}\text { weighted } \\
\%^{\mathrm{a}}\end{array}$ & $\mathbf{n}$ & $\begin{array}{c}\text { weighted } \\
\%^{\mathrm{a}}\end{array}$ & \\
\hline \multicolumn{6}{|c|}{ Problem of financial access to health care use } \\
\hline Yes & 674,844 & 45.9 & $1,073,301$ & 43.9 & \multirow{2}{*}{0.545} \\
\hline No & 796,630 & 54.1 & $1,370,651$ & 56.1 & \\
\hline \multicolumn{6}{|l|}{ Age, years } \\
\hline $18-45$ & 525,062 & 35.7 & 712,605 & 29.2 & \multirow{2}{*}{0.024} \\
\hline $46-64$ & 946,412 & 64.3 & $1,731,347$ & 70.8 & \\
\hline \multicolumn{6}{|l|}{ Sex } \\
\hline Male & 650,156 & 44.2 & $1,073,319$ & 43.9 & \multirow{2}{*}{0.936} \\
\hline Female & 821,318 & 55.8 & $1,370,633$ & 56.1 & \\
\hline \multicolumn{6}{|l|}{ Race and ethnicity } \\
\hline Non-Hispanic White & $1,257,664$ & 85.5 & $1,988,957$ & 81.4 & \multirow{4}{*}{0.046} \\
\hline Non-Hispanic Black & 137,885 & 9.4 & 354,129 & 14.5 & \\
\hline Hispanic & 21,109 & 1.4 & 17,472 & 0.7 & \\
\hline Others & 54,816 & 3.7 & 83,394 & 3.4 & \\
\hline \multicolumn{6}{|l|}{ Health status } \\
\hline Excellent or very good & 171,799 & 11.7 & 273,194 & 11.2 & \multirow{3}{*}{0.892} \\
\hline Good or fair & 999,068 & 67.9 & $1,693,956$ & 69.3 & \\
\hline Poor & 300,607 & 20.4 & 476,802 & 19.5 & \\
\hline \multicolumn{6}{|l|}{ Education } \\
\hline Below high school & 46,506 & 3.2 & 62,421 & 2.6 & \multirow{4}{*}{0.008} \\
\hline High school graduate & 382,575 & 26.0 & 879,161 & 36.0 & \\
\hline Some college & 633,860 & 43.1 & 953,115 & 39.0 & \\
\hline College graduate & 408,533 & 27.8 & 549,255 & 22.5 & \\
\hline \multicolumn{6}{|l|}{ Marital status } \\
\hline Married & 668,217 & 45.4 & $1,059,682$ & 43.4 & \multirow{4}{*}{0.223} \\
\hline Never married & 362,328 & 24.6 & 530,418 & 21.7 & \\
\hline Divorced or separated & 399,898 & 27.2 & 731,425 & 29.9 & \\
\hline Widowed & 41,031 & 2.8 & 122,427 & 5.0 & \\
\hline \multicolumn{6}{|l|}{ Family annual income } \\
\hline$\leq \$ 49,999$ & 735,428 & 50.0 & $1,347,991$ & 55.2 & \multirow{2}{*}{0.071} \\
\hline$\geq \$ 50,000$ & 736,046 & 50.0 & $1,095,961$ & 44.8 & \\
\hline \multicolumn{6}{|l|}{ Census region } \\
\hline Northeast & 185,245 & 12.6 & 409,577 & 16.8 & \multirow{4}{*}{0.086} \\
\hline Midwest & 428,318 & 29.1 & 586,672 & 24.0 & \\
\hline South & 555,757 & 37.8 & 874,241 & 35.8 & \\
\hline West & 302,154 & 20.5 & 573,462 & 23.5 & \\
\hline
\end{tabular}

of the NHIS is to monitor the health of the United States by collecting and analyzing data on a wide variety of health topics, such as health status, access to health care, insurance coverage, and socioeconomic and demographic factors. Survey respondents were included in our study if they were aged 18-64 years, had insurance coverage, and experienced cognitive impairment. Participants were excluded from the study if they were aged 65 years or older because of eligibility for Medicare.

\section{MEASUREMENTS}

Participants who answered "yes" to the survey question ("limited in any way because of difficulty remembering or because of experiencing periods of confusion") were identified as individuals with cognitive impairment. This assessment yielded accurate cognitive function estimates. ${ }^{22,23}$ Survey participants were also asked if they had a high-deductible plan. Participants who responded "yes" were assigned to the HDHP group; those who responded "no" were assigned to the non-HDHP group. Six indicators of problems with financial access to health care use were measured in the NHIS. Participants were asked if any of the following 6 situations had happened to them in the previous 12 months: They needed but could not afford medical care, dental care, eyeglasses, mental health care, follow-up care, and specialists. Participants were considered to have had overall financial access problems if the answer was "yes" for any of these 6 indicators.

\section{STATISTICAL ANALYSIS}

This study was a pooled cross-sectional study of cognitively impaired NHIS survey participants from 2010 to 2018. Considering the complex survey design in the NHIS, weights were applied to all analyses at the person level to obtain national estimates 


\section{TABLE 1 Baseline Characteristics of Individuals with Cognitive Impairment by HDHP (continued)}

\begin{tabular}{|c|c|c|c|c|c|}
\hline & \multicolumn{2}{|c|}{$\begin{array}{l}\text { HDHP group } \\
(n=1,471,474)\end{array}$} & \multicolumn{2}{|c|}{$\begin{array}{l}\text { Non-HDHP group } \\
(n=2,443,952)\end{array}$} & \multirow[b]{2}{*}{$P$ value } \\
\hline & $\mathbf{n}$ & $\begin{array}{c}\text { weighted } \\
\%^{\mathrm{a}}\end{array}$ & $\mathbf{n}$ & $\begin{array}{c}\text { weighted } \\
\%^{\mathrm{a}}\end{array}$ & \\
\hline \multicolumn{6}{|l|}{ BMI } \\
\hline$<18$ & 18,528 & 1.3 & 37,293 & 1.5 & \multirow{4}{*}{0.522} \\
\hline $18-24.9$ & 408,434 & 27.8 & 604,760 & 24.7 & \\
\hline $25-30$ & 480,873 & 32.7 & 770,264 & 31.5 & \\
\hline$>30$ & 563,639 & 38.3 & $1,031,635$ & 42.2 & \\
\hline \multicolumn{6}{|l|}{ Comorbidities } \\
\hline 0 & 406,561 & 27.6 & 727,605 & 29.8 & \multirow{4}{*}{0.789} \\
\hline 1 & 440,654 & 29.9 & 686,963 & 28.1 & \\
\hline 2 & 321,981 & 21.9 & 560,192 & 22.9 & \\
\hline$\geq 3$ & 302,278 & 20.5 & 469,192 & 19.2 & \\
\hline \multicolumn{6}{|l|}{ Insurance type } \\
\hline Any public insurance & 100,085 & 6.8 & $2,231,520$ & 91.3 & \multirow{3}{*}{0.285} \\
\hline Private insurance & $1,371,389$ & 93.2 & 212,432 & 8.7 & \\
\hline Uninsured & - & - & - & - & \\
\hline \multicolumn{6}{|l|}{ Year } \\
\hline 2010 & 84,412 & 5.7 & 319,489 & 13.1 & \multirow{9}{*}{$<0.001$} \\
\hline 2011 & 136,394 & 9.3 & 327,838 & 13.4 & \\
\hline 2012 & 131,113 & 8.9 & 231,137 & 9.5 & \\
\hline 2013 & 139,302 & 9.5 & 269,464 & 11.0 & \\
\hline 2014 & 162,005 & 11.0 & 255,576 & 10.5 & \\
\hline 2015 & 196,740 & 13.4 & 247,114 & 10.1 & \\
\hline 2016 & 167,566 & 11.4 & 226,672 & 9.3 & \\
\hline 2017 & 225,206 & 15.3 & 249,053 & 10.2 & \\
\hline 2018 & 228,736 & 15.5 & 317,609 & 13.0 & \\
\hline
\end{tabular}

aPercentages were computed using sampling weights

$B M I=$ body mass index; $H D H P=$ high-deductible health plan

(PERWEIGHT). The sample population was separated into HDHP and nonHDHP groups. For those enrolled in HDHP plans, we compared the trend between 2010 and 2018 in cognitively impaired individuals vs noncognitively impaired populations reported by others and the trend in financial access problems.

To evaluate the different types of financial access problems by HDHP enrollment, we used chi-square tests and multivariate logistic regressions to assess the effects of HDHP enrollment on financial access problems to health care use, adjusted for age, sex, race/ethnicity, health status, education, marital status, annual family earnings, region, body mass index, number of comorbidities, type of insurance, and year of survey. All processing and analysis of data were carried out using SAS version 9.4 (SAS Institute).

\section{Results}

Between 2010 and 2018, we identified 1,148 individuals who reported cognitive impairment, representing 3.9 million individuals in the United States. Of these, 424 (37.6\% weighted percentage) individuals reported HDHP enrollment, and 724 (62.4\%) did not report HDHP enrollment. The comparison of baseline characteristics between HDHP and non-HDHP groups is shown in Table 1. Compared with the non-HDHP group, those in the HDHP group were more likely to be aged 46-64 years, non-Hispanic White, and had some level of higher education. There was an increase in the prevalence of HDHP enrollment from $2010(20.9 \%)$ to $2018(41.9 \%)$ in individuals with cognitive impairments (Figure 1). In addition, problems with financial access to health care by those enrolled in HDHPs increased substantially, from $0.6 \%$ in 2010 to 42.1\% in 2018 (Figure 2).

Three types of financial access problems to health care for individuals with cognitive impairment were significantly different by HDHP enrollment between 2010 and 2018 (Figure 3). For medical care, 28.8\% reported access problems in the HDHP group compared with $19.4 \%$ in the non-HDHP group $(\mathrm{P}<0.001)$. For follow-up care, $18.2 \%$ reported access problems in the HDHP group compared with $9.4 \%$ in the non-HDHP group $(\mathrm{P}<0.001)$. For specialists, $20.3 \%$ reported access problems in the HDHP group compared with $12.8 \%$ in the non-HDHP group $(\mathrm{P}=0.002)$.

After controlling for possible confounding variables, individuals in the HDPH group were more likely to have overall financial access difficulties compared with those in the nonHDHP group (odds ratio $[\mathrm{OR}]=1.31$, $95 \% \mathrm{CI}=0.88-1.56, \mathrm{P}=0.271$ ), but it was statistically not significant (Table 2). For different types of financial access 


\section{FIGURE 1 High-Deductible Health Plan Enrollment Trend for Individuals with Cognitive Impairment During 2010-2018}

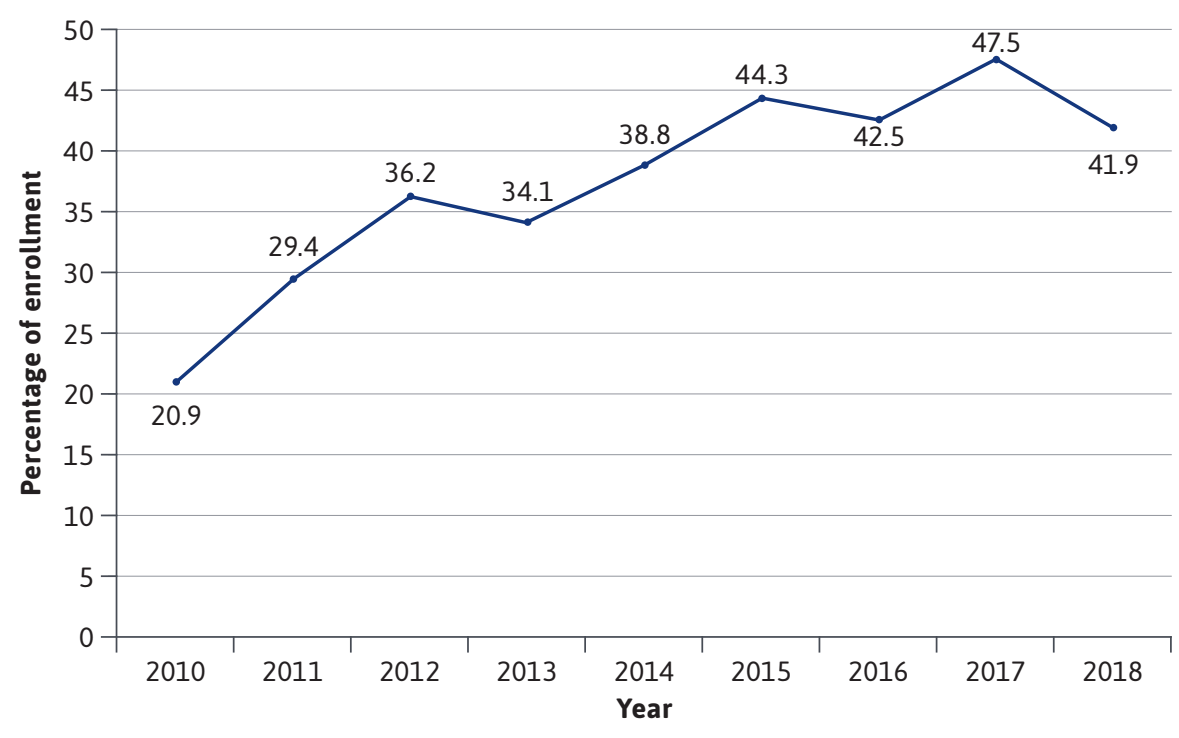

FIGURE 2 Trend for Problems of Financial Access to Health Care Use by High-Deductible Health Plan Status in Individuals with Cognitive Impairment During 2010-2018

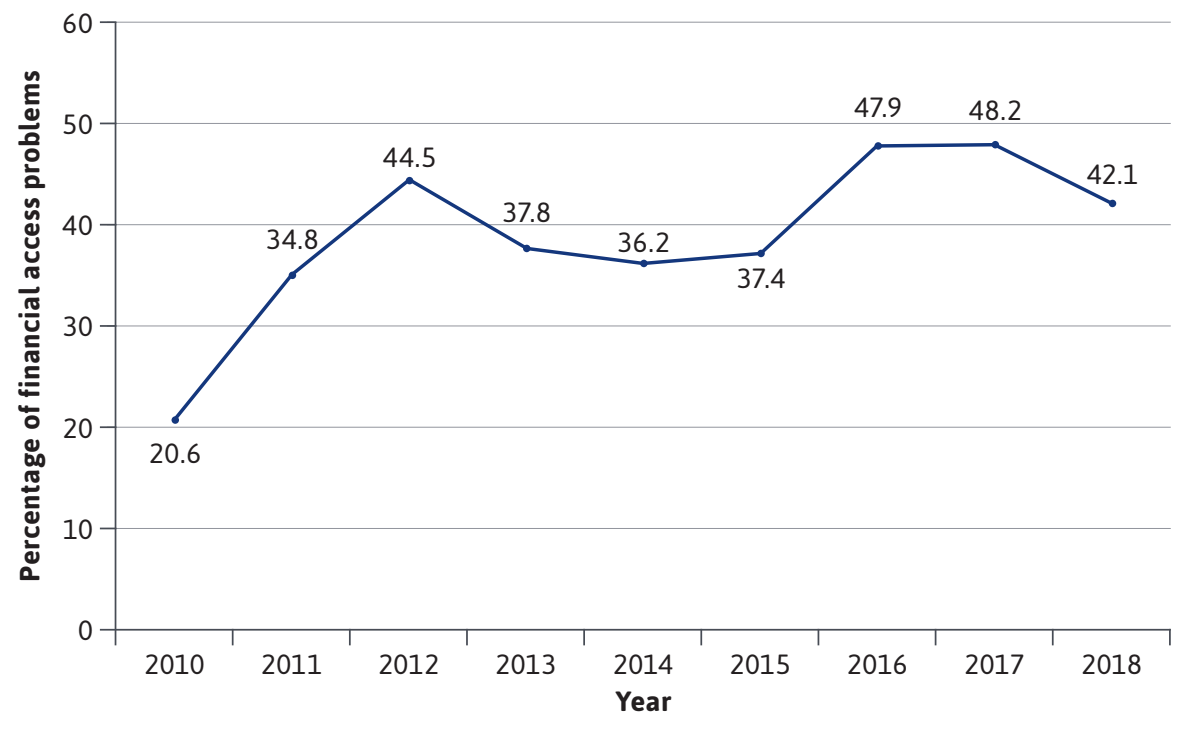

problems, those in the HDHP group were more likely to report problems in medical care $(\mathrm{OR}=1.84,95 \%$ $\mathrm{CI}=1.32-2.56, \mathrm{P} \leq 0.001)$; follow-up care $(\mathrm{OR}=2.37,95 \% \mathrm{CI}=1.42-3.95, \mathrm{P}=0.001)$; and specialists $(\mathrm{OR}=1.77,95 \% \mathrm{CI}=1.21-$ 2.59, $\mathrm{P}=0.004)$ compared with those in the non-HDHP group.

\section{Discussion}

Among participants aged 18-64 years, this study found that there was an increase in the prevalence of HDHP enrollment from 2010 to 2018 for individuals with cognitive impairment. The increase in HDHP participants in our study was consistent with previous studies. One study found that the enrollment in HDHPs among privatesector workers increased from $11.4 \%$ in 2006 to $46.5 \%$ in $2016 \% .{ }^{24}$ Moreover, according to the Bureau of Labor Statistics, the proportion of people enrolled in HDHPs increased from $24 \%$ in 2010 to $45 \%$ in $2018 .{ }^{25}$ This growth was expected, given that employers were increasingly expanding their use of HDHPs and that more adults in the United States obtained private health insurance from their employers. ${ }^{3,4}$

Another aspect that could influence HDHP enrollment was the rise in health care costs because increasing health care expenditures resulted in increased insurance premiums, leading employers to become more interested in HDHPs in order to cut costs on insurance premiums expenses. ${ }^{26}$ The trend of problems with financial access to health care used by HDHP status increased over the years. Several studies also reported a similar increase in financial access problems among HDHP enrollees for other chronic diseases. ${ }^{27-29}$ The increase in out-of-pocket costs may explain the increase in financial access issues. ${ }^{30}$

To the best of our knowledge, our research is the first to examine the association between financial access 


\section{FIGURE 3 Different Types of Financial Access Problems to Health Care Use by High-Deductible Health Plan Status in Individuals with Cognitive Impairment During 2010-2018}

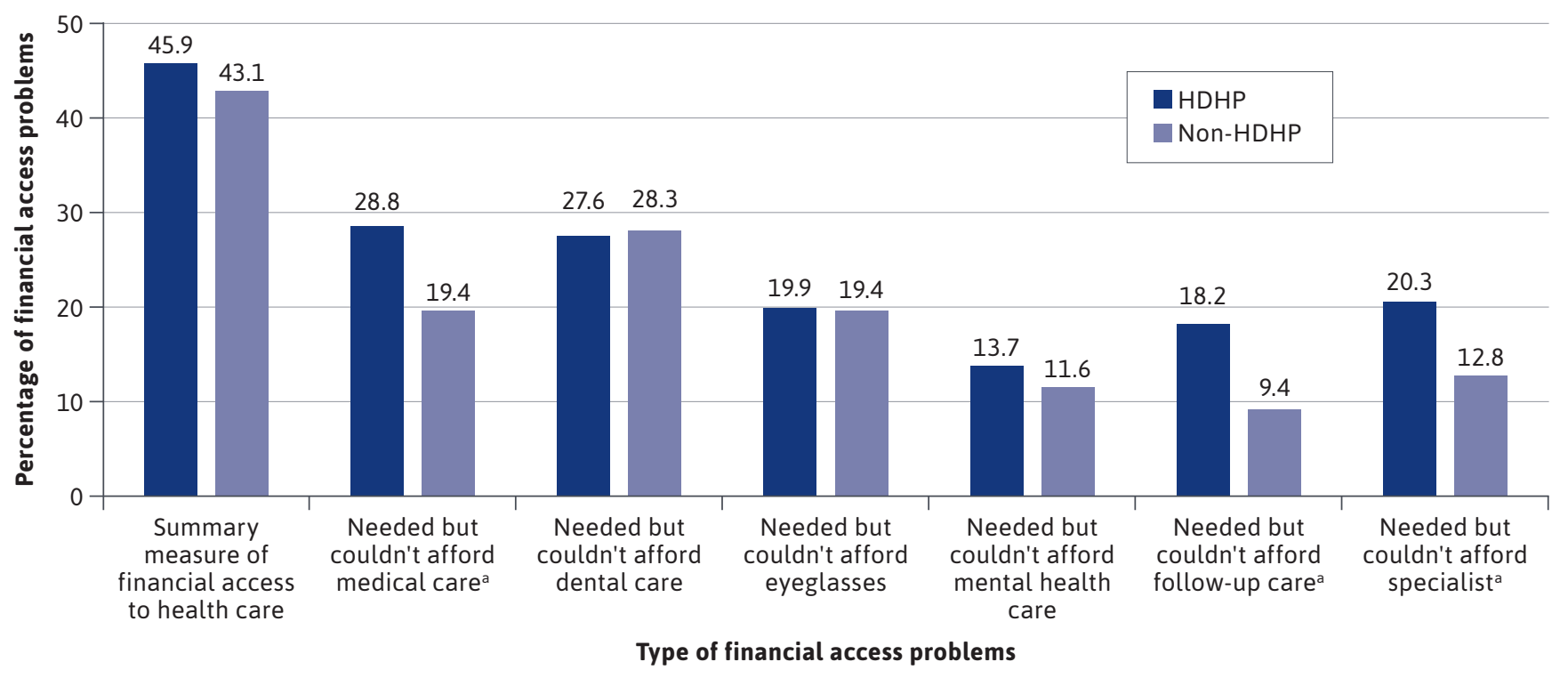

asignificant difference.

$H D H P=$ high-deductible health plan

problems and HDHP enrollment among individuals with cognitive impairment. We found that individuals with cognitive impairment with HDHPs were more likely to report overall financial access problems than those without HDHPs, but this difference was statistically not significant. HDHP participants had some financial access problems, including not being able to afford medical care, follow-up care, and specialists. The higher costs of health care among those with cognitive impairment may explain overall financial access problems. ${ }^{31}$ The excess out-of-pocket costs may have led to the avoidance of necessary medical care and the accumulation of high health care debt. ${ }^{32}$ Furthermore, individuals with cognitive impairment are also more prone to seek medical care, which may have resulted in greater financial access challenges. ${ }^{15}$ These challenges may also have influenced access to follow-up care and medical specialists, particularly if the patient developed dementia or had a permanent cognitive impairment that required frequent medical attention. ${ }^{33}$

We also found that HDHPs were not associated with the use of dental care, eyeglasses, and mental health care compared with non-HDHP participants. Cognitively impaired individuals may have a low self-awareness of their dental needs and may see dental care as a low priority. ${ }^{34}$
In addition, eyeglasses are not fully covered by HDHP, for which we found no association because of the limited coverage. ${ }^{35}$ Furthermore, in recent years, it has been easier to find affordable mental health care. ${ }^{36}$ The federal parity law requires comparable mental and physical health coverage if mental health services are offered. ${ }^{37}$

Stakeholders should be aware of problems with financial access to health care among individuals with cognitive impairment with HDHPs, since participation in an HDHP is a complicated decision. These individuals may confront an emergency and be unable to afford the out-of-pocket costs because of plan limitations. To avert financial access issues among HDHP enrollees, stakeholders must weigh the advantages against the expenses and forecast future costs.

Furthermore, policymakers need to provide special attention to those with cognitive impairment due to limited cognitive function in decision making by requiring the insurance companies to assist in HDHP enrollment, since cognitive impairment is considered one of the key risk factors for financial exploitation. ${ }^{38}$ The registration assistance could be provided in the form of brochures, videos, virtual calls, and phone calls for any questions and to explain the benefits of the plan. 


\section{TABLE 2}

\begin{tabular}{|c|c|c|c|}
\hline Financial access problem ${ }^{a}$ & OR & $95 \% \mathrm{Cl}$ & P value ${ }^{b}$ \\
\hline Overall financial access problems & 1.17 & $0.88-1.56$ & 0.271 \\
\hline Needed but couldn't afford medical care & 1.84 & $1.32-2.56$ & $<0.001$ \\
\hline Needed but couldn't afford dental care & 0.99 & $0.74-1.33$ & 0.934 \\
\hline Needed but couldn't afford eyeglasses & 1.12 & $0.77-1.61$ & 0.561 \\
\hline Needed but couldn't afford mental health care & 1.24 & $0.85-1.81$ & 0.259 \\
\hline Needed but couldn't afford follow-up care & 2.37 & $1.42-3.95$ & 0.001 \\
\hline Needed but couldn't afford specialists & 1.77 & $1.21-2.59$ & 0.004 \\
\hline \multicolumn{4}{|c|}{$\begin{array}{l}\text { aCovariates adjusted: age, gender, race/ethnicity, health status, education, marital status, family annual } \\
\text { income, census region, BMI, number of comorbidities, insurance type, and year. }\end{array}$} \\
\hline
\end{tabular}

Employers also should offer HDHP registration assistance, such as consultations, and host events to assist employees in choosing the appropriate plan. It is necessary to provide medical decision assistance, employee advocacy resources, and concierge services for managing the health care system in order to reduce costs. ${ }^{39}$ Individuals and families can better prepare for the financial challenges they may face during their participation in a health plan by becoming more informed of HDHP benefits. In addition, since caregivers are more involved with the patients and are more aware of patient situations, they should be included in the decisionmaking process for HDHP enrollment.

\section{LIMITATIONS}

There are some limitations to this study. Because of using survey data, this study was subject to participant reporting bias, which could have happened during the interviewing process. Participants might not have provided validated responses because of stigma. These participants might give desirable answers to the interviewer to avoid embarrassment. Also, if proxies participated during the survey process, the questions might have been interpreted and addressed differently by the proxies. Proxy measurement was likely common among participants with cognitive impairments to facilitate the interviewing process.

Since the assessment was based on survey responses, there was no information about the level of cognitive impairment (mild or severe). The level of cognitive impairment could have affected a person's ability to select an appropriate health plan. However, there is no evidence that individuals with cognitive impairment would choose high-deductible insurance unwisely. Future studies are warranted to identify the association between cognitive impairment and unwise choice of HDHPs.

\section{Conclusions}

HDHPs are supposed to facilitate efficient care options and reduce the costs of health care. However, our study found that individuals with cognitive impairment with HDHPs had some financial access problems, including the ability to afford medical care, follow-up care, and specialists. This issue should be taken into consideration by employers, health care policymakers, and caregivers. They need to be involved in the decision-making process and provide registration assistance for HDHP enrollment to improve health care access and minimize the cost.

\section{DISCLOSURES}

No outside funding supported this study. The authors have no conflicts of interest or financial interests to disclose.

\section{REFERENCES}

1. Healthcare.gov. High deductible health plan (HDHP). Accessed April 7, 2021. https://www.healthcare.gov/glossary/ high-deductible-health-plan/

2. Internal Revenue Service. Internal Revenue Bulletin: 2019-22. May 28, 2019. Accessed September 15, 2021. https:// www.irs.gov/irb/2019-22_irb

3. Grudzen CR, Brook RH. High-deductible health plans and emergency department use. JAMA. 2007; 297(10):1126-27.

4. Centers for Disease Control and Prevention. Health, United States, 2018 Data Finder. October 30, 2019. Accessed April 7, 2021. https://www.cdc.gov/nchs/ hus/contents2018.htm

5. Joshi P. High deductible health plans and outcomes for patients with diabetes: a realist review. Honors thesis. University of North Carolina. May 15, 2019. Accessed November 3, 2021. doi:10.17615/yc6r-yk60

6. Ehrbar A. Supply. Econlib. Accessed April 7, 2021. https://www.econlib.org/ library/enc/supply.html

7. Federal Reserve System, Board of Governers. Report on the economic well-being of U.S. households in 2016. May 2017. Accessed April 7, 2021. https:// www.federalreserve.gov/publications/ files/2016-report-economic-well-beingus-households-201705.pdf 
8. Galbraith AA, Soumerai SB, RossDegnan D, Rosenthal MB, Gay C, Lieu TA. Delayed and forgone care for families with chronic conditions in high-deductible health plans. J Gen Intern Med. 2012;27(9):1105-11.

9. Centers for Disease Control and Prevention. Cognitive impairment: a call for action, now! Febuary 2011. Accessed April 7, 2021. https://www.cdc.gov/aging/ pdf/cognitive_impairment/cogimp_poilicy_final.pdf

10. Plassman BL. Prevalence of cognitive impairment without dementia in the United States. Ann Intern Med. 2008;148(6):427-34.

11. Belbase A, Sanzenbacher GT. Cognitive aging and the capacity to manage money. Issue in Brief 17-1. Center for Retirement Research at Boston College. January 2017. Accessed July 8, 2021. http://hdl.handle. net/2345/bc-ir:107284

12. Lyketsos CG, Lopez O, Jones B, Fitzpatrick AL, Breitner J, Dekosky S. Prevalence of neuropsychiatric symptoms in dementia and mild cognitive impairment. JAMA. 2002;288(12):1475-83.

13. Tabert MH, Albert SM, BorukhovaMilov L, et al. Functional deficits in patients with mild cognitive impairment: prediction of AD. Neurology. 2002;58(5):758-64.

14. Albert SM, Glied S, Andrews H, Stern Y, Mayeux R. Primary care expenditures before the onset of Alzheimer's disease. Neurology. 2002;59(4):573-78.

15. Lugo-Palacios DG, Gannon B. Health care utilisation amongst older adults with sensory and cognitive impairments in Europe. Health Econ Rev. 2017;7(1):44.

16. Centers for Disease Control and Prevention. Self-reported increased confusion or memory loss and associated functional difficulties among adults aged $\geq 60$ years -21 states, 2011. MMWR Morb Mortal Wkly Rep. 2013;62(18):347-50.

17. Satizabal CL, Beiser AS, Chouraki V, Chêne G, Dufouil C, Seshadri S. Incidence of dementia over three decades in the Framingham Heart Study. N Engl J Med. 2016;374(6):523-32.
18. Langa KM, Larson EB, Karlawish JH, et al. Trends in the prevalence and mortality of cognitive impairment in the United States: is there evidence of a compression of cognitive morbidity? Alzheimers Dement. 2008;4(2):134-44.

19. Torisson G, Minthon L, Stavenow L, Londos E. Cognitive impairment is undetected in medical inpatients: a study of mortality and recognition amongst healthcare professionals. BMC Geriatr. 2012;12:47.

20. Chen X, Han Y, Zhou J, Ma M, Liu X. Diagnostic accuracy of cognitive screening tools under different neuropsychological definitions for poststroke cognitive impairment. Brain Behav. 2020; 10(8):e01671.

21. Centers for Disease Control and Prevention. About the National Health Interview Survey. September 16, 2020. Accessed May 31, 2021. https://www.cdc. gov/nchs/nhis/about nhis.htm

22. Bernstein AB, Remsburg RE. Estimated prevalence of people with cognitive impairment: results from nationally representative community and institutional surveys. Gerontologist. 2007;47(3):350-54.

23. Luo H, Yu G, Wu B. Self-reported cognitive impairment across racial/ethnic groups in the United States, National Health Interview Survey, 1997-2015. Prev Chronic Dis. 2018;15:E06.

24. Miller GE, Vistnes JP, Rohde F, Keenan PS. High-deductible health plan enrollment increased from 2006 to 2016, employer-funded accounts grew in largest firms. Health Aff (Millwood). 2018;37(8):1231-37.

25. US Bureau of Labor Statistics. Employee Benefits Survey. High deductible health plans and health savings accounts. 2018. Accessed May 31, 2021. https://www.bls.gov/ncs/ebs/factsheet/ high-deductible-health-plans-and-healthsavings-accounts.htm

26. Dolan R. High-deductible health plans. Health Affairs. February 4, 2016. Accessed April 7, 2021. https://www.healthaffairs. org/do/10.1377/hpb20160204.950878/ full/
27. Cohen RA, Zammitti EP. National Center for Health Statistics. Highdeductible health plans and financial barriers to medical care: early release of estimates from the National Health Interview Survey, 2016. June 2017. Accessed May 31, 2021. https://www.cdc. gov/nchs/data/nhis/earlyrelease/erhdhp_access_0617.pdf

28. Kielb ES, Rhyan CN, Lee JA. Comparing health care financial burden with an alternative measure of unaffordability. Inquiry. 2017;54:46958017732960. doi:10.1177/0046958017732960

29. Larson K, Gottschlich EA, Cull WL, Olson LM. High-deductible health plans for US children: trends, health service use, and financial barriers to care. Acad Pediatr. March 10, 2021. Epub ahead of print. doi:10.1016/j.acap.2021.03.001

30. Hayes SL, Collins SR, Radley DC. How much U.S. households with employer insurance spend on premiums and outof-pocket costs: a state-by-state look. Commonwealth Fund. May 23, 2019. Accessed June 2, 2021. https://www. commonwealthfund.org/publications/ issue-briefs $/ 2019 / \mathrm{may} /$ how-much-ushouseholds-employer-insurance-spendpremiums-out-of-pocket

31. Leibson CL, Long KH, Ransom JE, et al. Direct medical costs and source of cost differences across the spectrum of cognitive decline: a population-based study. Alzheimers Dement. 2015;11(8):917-32.

32. Pollitz K, Cox C, Lucia K, Keith K. Medical debt among people with health insurance. January 7, 2014. Accessed November 19, 2021. https://www.kff.org/ private-insurance/report/medical-debtamong-people-with-health-insurance/

33. Alzheimer's Association. Planning for care costs. 2021. Accessed June 3, 2021. https://www.alz.org/help-support/ caregiving/financial-legal-planning/ planning-for-care-costs

34. Wu B, Plassman BL, Liang J, Wei L. Cognitive function and dental care utilization among community-dwelling older adults. Am J Public Health. 2007;97(12):2216-21. 
35. Evans L. All about vision. What can I spend my HSA on? January 20, 2021. Accessed June 3, 2021. https://www. allaboutvision.com/vision-insurance/ items-you-can-spend-with-hsa/

36. Hobson K, Levine H. 5 ways to save on the mental-health care you need. December 9, 2014. Accessed June 3, 2021. https://money.com/ mental-health-care-insurance-saving/
37. Roberts-Grey G. Are mental health services and therapy covered by health insurance? May 13, 2020. Accessed June 3, 2021. https://www.goodrx.com/blog/ mental-health-insurance-how-to-gethelp/

38. Wood S, Lichtenberg PA. Financial capacity and financial exploitation of older adults: research findings, policy recommendations and clinical implications. Clin Gerontol. 2016;40(1):3-13.
39. Daly R. Health plan payment and reimbursement. Enrollment of large-company workers in high-deductible plans reaches a historic high. Healthcare Financial Management Association. August 14, 2019. Accessed June 3, 2021. https:// www.hfma.org/topics/news/2019/08/ enrollment-of-large-company-workersin-high-deductible-plans-rea.html 